\title{
Heat shock-induced activation of stress MAP kinase is regulated by threonine- and tyrosine-specific phosphatases
}

\author{
Aaron Ngocky Nguyen and Kazuhiro Shiozaki ${ }^{1}$ \\ Section of Microbiology, University of California, Davis, California 95616 USA
}

\begin{abstract}
In eukaryotic species from yeast to human, stress-activated protein kinases (SAPKs), members of a MAP kinase (MAPK) subfamily, regulate the transcriptional response to various environmental stress. It is poorly understood how diverse forms of stress are sensed and transmitted to SAPKs. Here, we report the heat shock regulation of the fission yeast Spc1 SAPK, a homolog of human p38 and budding yeast Hog1p. Although osmostress and oxidative stress induce strong activation of the Wis1 MAPK kinase (MEK), which activates Spc1 through Thr-171/Tyr-173 phosphorylation, activation of Wis1 upon heat shock is relatively weak and transient. However, in heat-shocked cells, Pyp1, the major tyrosine phosphatase that dephosphorylates and inactivates Spc1, is inhibited for its interaction with Spc1, which leads to strong activation of Spc1. Subsequently, Spc1 activity is rapidly attenuated by Thr-171 dephosphorylation, whereas Tyr-173 remains phosphorylated. Thr-171 dephosphorylation is compromised in a strain lacking functional type 2C serine/threonine phosphatases (PP2C), Ptc1 and Ptc3. Moreover, Ptc1 and Ptc3 can dephosphorylate Thr-171 of Spc1 both in vivo and in vitro. These observations strongly suggest that PP2C enzymes play an important role in the attenuation of Spc1 activity in heat-shocked cells. Thus, transient activation of Spc1 upon heat shock is ensured by differential regulation of threonine and tyrosine phosphorylation.
\end{abstract}

[Key Words: Heat shock; protein phosphatase 2C; protein tyrosine phosphatase; Schizosaccharomyces pombe; Spc1; stress-activated protein kinase]

Received April 15, 1999; revised version accepted May 21, 1999.

A MAP kinase (MAPK) cascade is an intracellular signaling module ubiquitous among eukaryotes. The basic mechanism of signal transduction appears to be very similar in all MAPK cascades (Marshall 1995); MAPK is activated by dual phosphorylation of neighboring threonine and tyrosine residues within protein kinase subdomain VIII, which is carried out by a threonine/tyrosinekinase, MAPK kinase (MEK). MEK is activated in turn by an upstream MEK kinase (MEKK) also through phosphorylation of the conserved serine/threonine residues in subdomain VIII. Thus, signals are transmitted by sequential activation of the protein kinases, MEKK $\rightarrow$ MEK $\rightarrow$ MAPK. Cells from yeast to human utilize multiple MAPK cascades to transmit diverse extracellular stimuli to the nucleus (Waskiewicz and Cooper 1995). MAPKs dedicated for stress signaling are generically called SAPKs (stress-activated protein kinases). SAPKs include highly homologous Hoglp in budding yeast Saccharomyces cerevisiae (Brewster et al. 1993), Spc1 (also known as Sty1 or Phh1) in fission yeast Schizosaccharomyces pombe (Millar et al. 1995; Shiozaki and Russell 1995b; Kato et al. 1996), and mammalian p38 (Han et al. 1994).

${ }^{1}$ Corresponding author.

E-MAIL kshiozaki@ucdavis.edu; FAX (530) 752-9014.
S. pombe spc1 (suppressor of phosphatase 2C) was first identified as a suppressor mutation of the phenotypes caused by loss of type $2 \mathrm{C}$ serine/threonine phosphatases (PP2Cs) encoded by $p t c 1^{+}$and $p t c 3^{+}$(Shiozaki and Russell 1995a). The same genetic screen also isolated mutations in wis $1^{+}$, which encodes a MEK homolog implicated in cell cycle regulation (Warbrick and Fantes 1991). Subsequent genetic and biochemical analyses demonstrated that Wis1 is the MEK that phosphorylates Thr171/Tyr-173 of Spc1 (Millar et al. 1995; Shiozaki and Russell 1995b). Wis1 activity is counteracted by tyrosine-specific phosphatases, Pyp1 and Pyp2 (Millar et al. 1995; Shiozaki and Russell 1995b). Pyp1 accounts for the major cellular activity that dephosphorylates Spc1 Tyr173, with Pyp2 having a minor role (Degols et al. 1996; Samejima et al. 1997). Because MAPK activation requires both threonine and tyrosine phosphorylation (Cobb and Goldsmith 1995), dephosphorylation of Tyr173 is sufficient to inactivate Spc1. Simultaneous deletion of $p y p 1^{+}$and $p y p 2^{+}$brings about Spc1 hyperactivation lethal to the cell (Millar et al. 1995; Shiozaki and Russell 1995b), indicating that dephosphorylation of Tyr-173 by Pyp1/Pyp2 is central to negative regulation of Spc1. On the other hand, Thr-171 dephosphorylation of Spc1 has never been carefully examined. Whereas in- 
activation of MAPKs by tyrosine phosphatases has also been reported in budding yeast and mammals (Keyse 1998), many MAPK phosphatases belong to the dualspecificity phosphatase family, which dephosphorylates both the threonine and tyrosine residues (Clarke 1994; Keyse 1995).

Like mammalian p38 (Kyriakis and Avruch 1996), Spc1 is activated in response to diverse stress stimuli including high osmolarity, oxidative stress, and heat shock (Millar et al. 1995; Shiozaki and Russell 1995b; Degols et al. 1996). $\Delta s p c 1$ mutants are supersensitive to these stress conditions, indicating that the function of Spc1 is crucial for cellular resistance to multiple forms of stress. Spc1 is not phosphorylated at all in $\Delta$ wis $1 \mathrm{mu}-$ tants under any stress conditions, which suggests that Wis1 is the only MEK for Spc1 (Millar et al. 1995; Shiozaki and Russell 1995b; Degols et al. 1996). However, it has yet to be determined whether Wis 1 is activated by all the stress conditions that are known to activate Spc1. To examine whether various stress stimuli are transmitted to the Wis1 MEK through MEKKs, we previously performed mutational analyses of the MEKK phosphorylation sites in Wis1 (Shiozaki et al. 1998). Ser469 and Thr-473 of Wis1, which correspond to the MEKK phosphorylation sites conserved among various MEKs, were substituted with alanine and aspartic acid to create wis1AA and wis1DD mutants, respectively. As in the $\Delta$ wis1 strain, Spc1 phosphorylation was not detectable in the wis1AA mutant under various stress conditions, demonstrating that Ser-469 and Thr-473 are crucial for Wis 1 activation. In wis1DD mutant cells, Spc1 phosphorylation was higher than in wild-type cells even in the absence of stress, which suggests that the wis1DD mutation partially stimulates Wis 1 activity presumably by mimicking phosphorylation of Ser-469/Thr-473. However, high osmolarity and oxidative stress failed to induce further activation of Spcl in wis $1 D D$ cells. These results suggest that osmostress and oxidative stress signals are mediated by MEKKs through phosphorylation of Ser-469/Thr-473 of Wis1, and substitution of these sites with unphosphorylatable residues abolishes signaling to Spc1. To our surprise, heat shock induced strong activation of Spc1 in wis1DD cells as well as in wild-type cells, indicating that heat shock signals can be transmitted to Spc1 independently of MEKKs. It should be noted, however, that heat shock-induced activation of Spc1 still requires Wis1 MEK activity, as Spc1 is not activated at all in $\Delta$ wis1 and wis $1 A A$ mutants even after heat shock (Degols et al. 1996; Shiozaki et al. 1998).

With the aim of understanding how heat shock stimuli are transmitted to Spc1, we developed an in vitro assay for Wis1 to examine how the catalytic activity of Wis1 and Wis1DD is regulated in response to heat shock. We found that Wis 1 activation upon heat shock is relatively weak and transient, which contrasts with strong Wis1 activation induced by osmostress and oxidative stress. The activity of Wis1DD is constitutive and not affected by heat shock, suggesting that heat shock-induced activation of Spc1 in the wis1DD strain is not mediated by an increase of Wis1DD activity. On the other hand, the tyrosine phosphatase activity that dephosphorylates Spc1 Tyr-173 is significantly inhibited in heat-shocked cells. We found that heat shock impairs the interaction of the Pyp1 tyrosine phosphatase with Spc1. These results strongly suggest that Spc1 activation upon heat shock is partly mediated by inhibition of the tyrosine phosphatases dephosphorylating Spc1. Importantly, Spc1 activated in heat-shocked cells is rapidly attenuated by Thr-171 dephosphorylation, whereas Tyr-173 remains phosphorylated. Genetic and biochemical data strongly suggest that PP2C enzymes, Ptc1 and Ptc3, dephosphorylate Spc1 Thr-171. Thus, transient activation of the Spc1 SAPK upon heat shock is ensured by differential regulation of Thr-171 and Tyr-173 phosphorylation by PP2C and tyrosine-specific phosphatases.

\section{Results}

Stress-induced activation of the Wis1 MEK

To determine whether the catalytic activity of Wis 1 is regulated in response to various stress stimuli that activate Spc1, we developed an in vitro assay for Wis1. Wis1 was purified by immunoprecipitation from a strain in which chromosomal wis $1^{+}$is tagged with the sequence encoding the myc epitope (Shiozaki et al. 1998). Activity of Wis1 was measured using the glutathione $S$-transferase (GST)-Spc1 fusion protein as substrate (see Materials and Methods). Anti-phosphotyrosine (pTyr) immunoblotting showed weak phosphorylation of GST-Spc1 by Wis1 isolated from unstressed cells (Fig. 1A, lane 1). On the other hand, GST-Spcl was strongly phosphorylated when incubated with Wis 1 purified from cells exposed to osmostress by $0.6 \mathrm{M} \mathrm{KCl}$ (Fig. 1A, lane 2) or oxidative stress by $0.3 \mathrm{~mm} \mathrm{H}_{2} \mathrm{O}_{2}$ (lane 3 ) for $10 \mathrm{~min}$. This result indicates that osmostress and oxidative stress induce activation of the Wis1 MEK.

In addition to osmostress and oxidative stress, Spc1 is also activated when cells are exposed to heat shock by shifting the growth temperature from $30^{\circ} \mathrm{C}$ to $48^{\circ} \mathrm{C}$ (Degols et al. 1996). Under this condition, $\Delta$ wis 1 and $\Delta s p c 1$ mutants lose viability more quickly than wild-type cells, indicating that Spc1 activity is crucial for thermotolerance (Degols et al. 1996; Kato et al. 1996). Using the assay described above, we measured the activity of Wis1 isolated from cells heat-shocked by the temperature shift from $30^{\circ} \mathrm{C}$ to $48^{\circ} \mathrm{C}$. Compared with Wis 1 activation by osmostress and oxidative stress, relatively weak, transient activation of Wis 1 was observed in response to heat shock (Fig. 1B, lanes 1-4). Wis1 activity became undetectable within $10 \mathrm{~min}$ after the temperature shift.

We also assayed the activity of Wis1DD, which has aspartic acid substitutions at Ser-469/Thr-473, the conserved phosphorylation sites by MEKKs (Shiozaki et al. 1998). The Wis1DD protein was immunoprecipitated with anti-myc antibodies before and after the stress treatments from a strain in which chromosomal wis $1^{+}$ was replaced with the wis1DD gene tagged with the myc epitope sequence (Shiozaki et al. 1998). Wis1DD from unstressed cells showed high activity comparable to 
A

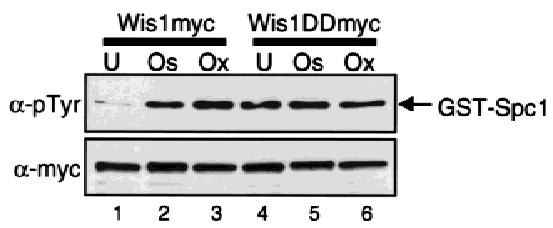

B

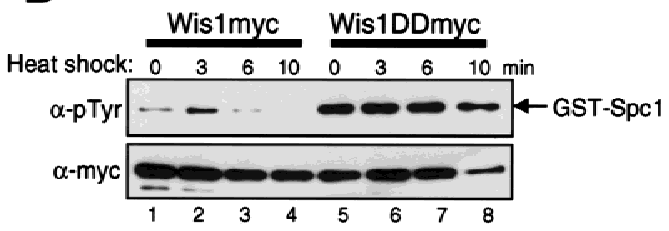

Figure 1. Activity of the wild-type and constitutively active mutant of the Wis1 MEK under stress conditions. Strains carrying the wis1:myc (KS1878) or wis1DD:myc (KS2125) alleles were grown to mid-log phase at $30^{\circ} \mathrm{C}$ in YES medium and exposed to various forms of stress. Wis 1 myc and Wis1DDmyc, which have 12 copies of the myc tag at the carboxy-terminus, were purified by anti-myc immunoprecipitation, and their catalytic activity was measured with GST-Spc1 as substrate. Phosphorylation of GST-Spc1 was detected by immunoblotting with anti-phosphotyrosine ( $\alpha$-pTyr) antibodies. Anti-myc ( $\alpha$-myc) immunoblotting shows the amount of immunoprecipitated Wislmyc and Wis1DDmyc in the assay. (A) Activity of Wis1myc and Wis1DDmyc purified from unstressed cells $(\mathrm{U})$ and cells exposed to osmotic $(0.6 \mathrm{M} \mathrm{KCl}$ for $10 \mathrm{~min}$; Os) or oxidative $\left(0.3 \mathrm{mM} \mathrm{H}_{2} \mathrm{O}_{2}\right.$ for $10 \mathrm{~min}$; $\left.\mathrm{Ox}\right)$ stress. (B) Activity of Wis 1 myc and Wis1DDmyc after the culture temperature was shifted from $30^{\circ} \mathrm{C}$ to $48^{\circ} \mathrm{C}$ at time 0 . No significant change in Wis1DD activity was detected after the stress treatments in repeated experiments.

stress-activated Wis1, but Wis1DD activity did not increase after osmostress, oxidative stress (Fig. 1A, lanes 4-6), and heat shock (Fig. 1B, lanes 5-8). Thus, aspartic acid substitutions of the MEKK phosphorylation sites make Wis1 constitutively active and unresponsive to the stress conditions tested. These results strongly suggest that the catalytic activity of the Wis1 MEK is regulated by MEKKs in response to stress stimuli.

\section{Tyrosine dephosphorylation of Spc1 is inhibited in heat-shocked cells}

The results described above indicate that activity of Wis1DD does not change significantly upon stress stimuli, which is consistent with the observation that the level of Spcl activation in the wis1DD mutant strain is not affected by osmostress and oxidative stress (Shiozaki et al. 1998). In contrast, we found previously that tyrosine phosphorylation of Spc1 increases significantly upon heat shock in both wild-type and wis1DD mutant strains (Shiozaki et al. 1998; see Fig. 3C). One hypothesis to explain the induced tyrosine phosphorylation of Spc1 without a significant increase in Wis1DD activity is that the tyrosine phosphatases dephosphorylating Spc1 are inhibited upon heat shock. To test this hypothesis, tyrosine dephosphorylation of Spc1 after heat shock was examined with a strain in which chromosomal spc1 $1^{+}$is tagged with the $\mathrm{HA} 6 \mathrm{H}$ sequence encoding two copies of hemagglutinin (HA) and six histidine residues (Shiozaki and Russell 1995b). Cells grown at $30^{\circ} \mathrm{C}$ were exposed to heat shock at $48^{\circ} \mathrm{C}$ for $10 \mathrm{~min}$ to induce tyrosine phosphorylation of Spc1 (Fig. 2A, lane labeled HS). The culture was then shifted back to $30^{\circ} \mathrm{C}$, and tyrosine phosphorylation of Spc1 was monitored by anti-phosphotyrosine immunoblotting. The level of Spc1 tyrosine phosphorylation remained high until some decrease was detected after $3 \mathrm{hr}$ of recovery at $30^{\circ} \mathrm{C}$ (Fig. 2A). Wis 1 activity was undetectable after $10 \mathrm{~min}$ of heat shock and the temperature shift to $30^{\circ} \mathrm{C}$ did not significantly activate Wis1 (data not shown). This result contrasts with rapid dephosphorylation of Spc1 after osmostress; tyrosine phosphorylation of Spc1 returns to the basal level within 50 min even under continuous high osmolarity stress (Gaits et al. 1997). Therefore, this result indicates that tyrosine dephosphorylation of Spc1 is inhibited in cells treated by a brief heat shock, which is consistent with the idea that inhibition of the tyrosine phosphatases for Spcl contributes to Spcl activation in response to heat shock.

Spc1 is dephosphorylated by two tyrosine-specific phosphatases, Pyp1 and Pyp2, with Pyp1 having the major activity (Millar et al. 1995; Shiozaki and Russell 1995b; Degols et al. 1996). Therefore, we examined whether Pyp1 function is inhibited in response to heat shock. In strains overexpressing $p y p 1^{+}$from a strong promoter, Spc1 tyrosine phosphorylation is suppressed completely even after osmostress (Millar et al. 1995; Shiozaki and Russell 1995b). A spc1:HA6H strain was transformed with the pREP1-pyp1HA6H plasmid (Shiozaki and Russell 1995b), which expresses Pyp1 with a carboxy-terminal HA6H tag under the control of the thiamine (vitamin $\mathrm{B}_{1}$ )-repressible $n m t 1$ promoter (Maundrell 1990). The transformant was grown at $30^{\circ} \mathrm{C}$ in the presence and absence of thiamine and treated with osmostress by $0.6 \mathrm{M} \mathrm{KCl}$ or heat shock at $48^{\circ} \mathrm{C}$. Spc1 and Pyp 1 were purified by Ni-NTA chromatography under denaturing conditions for immunoblotting with anti-phosphotyrosine and anti-HA antibodies. Pyp1 was highly overexpressed under thiamine depletion $\left(-\mathrm{B}_{1}\right)$, which completely inhibited Spc1 tyrosine phosphorylation upon osmostress (Fig. 2B, lanes labeled Os). In contrast, overexpressed Pyp1 showed little effect on Spc1 phosphorylation induced by heat shock (Fig. 2B). This observation suggests that dephosphorylation of Spc1 by Pyp1 is strongly inhibited in heat-shocked cells.

To explore further the inhibition of Pyp1 by heat shock, the in vivo interaction of Pyp1 with Spc1 was probed by use of the pyp1-C470S mutation before and after heat shock. Pyp1 with Cys-470 substituted with serine $\left(\mathrm{Pyp}^{\mathrm{C} 470 \mathrm{~S}}\right)$ is catalytically inactive but stably interacts with the substrate, Spc1 (Shiozaki and Russell 1995b). The chromosomal pyp $1^{+}$locus was replaced with the pyp1-C470S mutant gene, which was tagged with the sequence encoding the myc epitope for detection with anti-myc antibodies. Phenotypes of the control 
Figure 2. Dephosphorylation of Spc1 Tyr-173 is inhibited in heatshocked cells. (A) Wild-type strain (KS2096) carrying chromosomal $s p c 1^{+}$tagged with the $\mathrm{HA} 6 \mathrm{H}$ sequence was grown to mid-log phase in YES medium at $30^{\circ} \mathrm{C}$. The culture was shifted to $48^{\circ} \mathrm{C}$ for 10 min (heat shock, HS) to induce Spc1 tyrosine phosphorylation and then shifted back to $30^{\circ} \mathrm{C}$ (Recovery). Aliquots of cells were harvested at the indicated time points, and Spcl was purified by Ni-NTA chromatography. The level of Spc1 tyrosine phosphorylation was examined by immunoblotting with anti-phosphotyrosine antibodies. No tyrosine dephosphorylation of Spcl was detected $>2 \mathrm{hr}$ after the temperature shift down. (B) Overexpression of the Pyp1 tyrosine phosphatase cannot suppress Spc1 activation induced by heat shock. Wild-type strain (KS1376) carrying chromosomal spc1 $1^{+}$tagged with the HA6H sequence was transformed with pREP1-pyp1HA6H, which expresses Pyp1 with a carboxy-terminal $\mathrm{HA} 6 \mathrm{H}$ tag under the control of the thiamine-repressible $n m t 1$ promoter. The transformant was grown in EMM 2 medium at $30^{\circ} \mathrm{C}$ in the presence $\left(+\mathrm{B}_{1}\right)$ and absence $\left(-\mathrm{B}_{1}\right)$ of thiamine (vitamin $\mathrm{B}_{1}$ ) for $18 \mathrm{hr}$ and exposed to osmostress by $0.6 \mathrm{M} \mathrm{KCl}$ for $10 \mathrm{~min}$ (Os) or heat shock at $48^{\circ} \mathrm{C}$ for 5, 10, and $20 \mathrm{~min}$. Spc1 and Pyp1 were purified by Ni-NTA chromatography under denaturing conditions and analyzed by immunoblotting with anti-phosphotyrosine and anti-HA antibodies. In the absence of thiamine, overexpressed Pyp1 completely suppressed Spcl tyrosine phosphorylation upon osmostress but showed little activity in heat-shocked cells. (C) The Pyp1 tyrosine phosphatase rapidly loses its ability to interact with Spcl after heat shock. Strain CA187 has chromosomal pyp1+ replaced with pyp1C470S:myc to express the catalytically inactive Pyp $1^{\mathrm{C} 470 \mathrm{~S}}$ with a carboxy-terminal myc epitope tag. This strain was transformed with pREP1-GST-Spc1 and grown at $30^{\circ} \mathrm{C}$ in EMM2 medium without thiamine to induce expression of GST-Spc1 from the thiaminerepressible $n m t 1$ promoter. Cells were exposed to heat shock at $48^{\circ} \mathrm{C}$ (left) or osmostress by $0.6 \mathrm{M} \mathrm{KCl}$ (right), and aliquots of cells were harvested at the indicated time points. Cell lysates were absorbed to GSH-Sepharose beads, and, after extensive washes, proteins bound to the beads (GSH-Beads) were analyzed by immunoblotting with anti-myc and anti-GST antibodies. The amount of Pyp1 ${ }^{\mathrm{C} 470 \mathrm{~S}}$ detected in the crude lysates (Lysate) did not change significantly after the stress treatments.

strain expressing wild-type Pyp1 tagged with the myc epitope were indistinguishable from those of cells expressing untagged Pyp1, indicating that the Pyp1 function was not disturbed by the myc epitope /data not shown). The GST-Spc1 fusion protein was expressed from the pREP1-GST-Spc1 plasmid in this pyp1C470S:myc strain, and cell lysates were incubated with glutathione (GSH)-Sepharose beads. The Pyp1 ${ }^{\text {C470S }}$ protein was copurified with GST-Spc1 on GSH-beads (Fig. 2C, time 0) as reported previously (Shiozaki and Russell 1995b). When this strain was exposed to heat shock, the amount of Pyp1 ${ }^{\text {C470S }}$ bound to GST-Spc1 decreased significantly within $5 \mathrm{~min}$ and became undetectable by 20 min after heat shock (Fig. 2C, left). On the other hand, osmostress showed no effect on the amount of Pyp $1^{\mathrm{C} 470 S}$ coprecipitated with GST-Spc1 (Fig. 2C, right). Thus, heat shock, but not osmostress, inhibits the interaction between Pyp1 and Spc1. We also found that the GSTSpc1 fusion protein immobilized on GSH-beads can precipitate Pyp1 ${ }^{\mathrm{C} 470 \mathrm{~S}}$ from lysates of unstressed cells but not from those of heat-shocked cells (data not shown). Taken together, these results strongly suggest that heat shock impairs the ability of Pyp1 to interact with its substrate, Spc1.

Spc1 activity is rapidly attenuated by Thr-171 dephosphorylation in heat-shocked cells

As shown in Figure 2B, the level of activating tyrosine
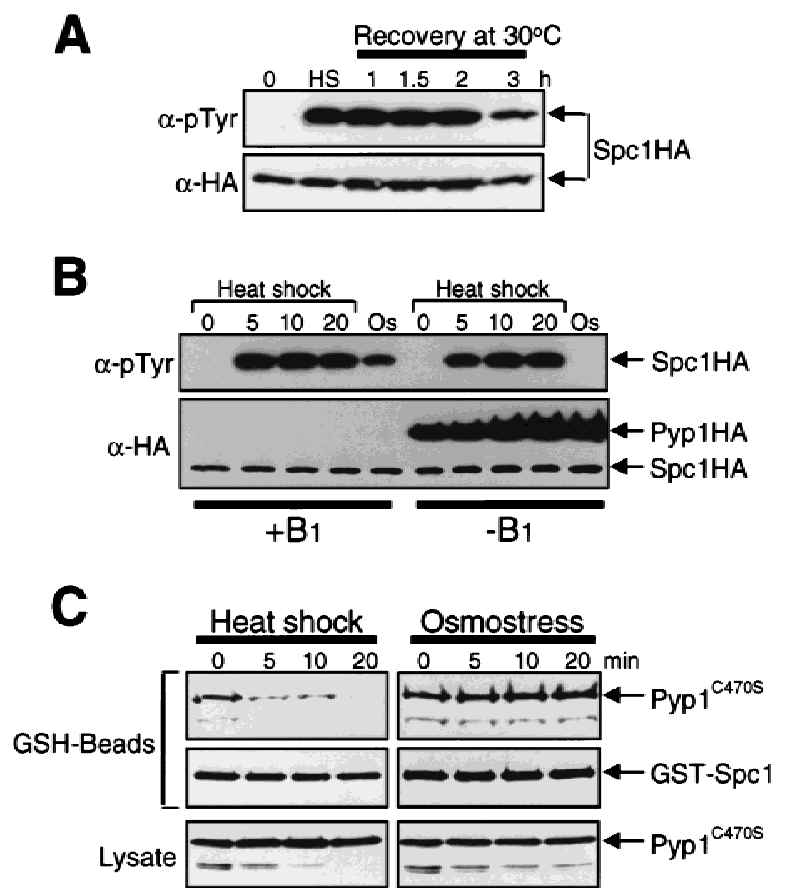
A

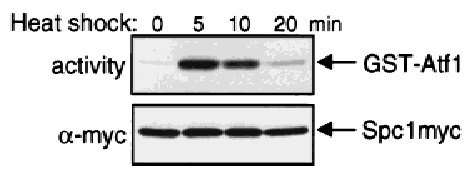

B
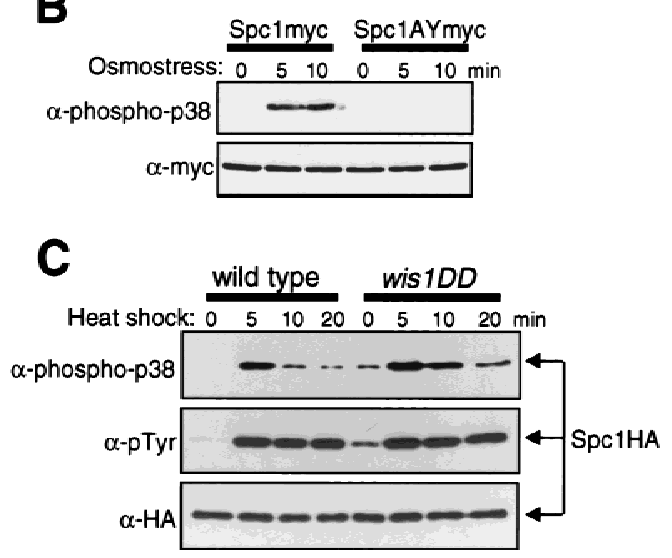

Figure 3. The dual-phosphorylated, active form of Spc1 accumulates only transiently in response to heat shock. (A) Transient activation of Spc1 after heat shock. Strain GD1942, in which chromosomal $s p c 1^{+}$is tagged with the sequence encoding the myc epitope, was grown to mid-log phase in YES medium at $30^{\circ} \mathrm{C}$ and then shifted to $48^{\circ} \mathrm{C}$ at time 0 . Aliquots of cells were harvested at the indicated time points, and $\mathrm{Spcl}$ was purified by anti-myc immunoprecipitation. Activity of Spcl was assayed by incubation with the substrate GST-Atf1 in the presence of $\mathrm{Mg}^{2+}$ and $\left[\gamma_{-}{ }^{32} \mathrm{P}\right]$ ATP, and was analyzed by SDS-PAGE and autoradiography (top). Anti-myc immunoblotting shows the amount of immunoprecipitated Spc1 in the assays (bottom). (B) Antibodies against dual-phosphorylated mammalian p38 cross react with Spc1 phosphorylated on both Thr-171 and Tyr-173. Strains expressing the myc-tagged wild-type Spcl (GD1942) or Spc1AY (CA140), which has Thr-171 substituted with unphosphorylatable alanine, were grown in YES medium at $30^{\circ} \mathrm{C}$ and then exposed to osmostress by $0.6 \mathrm{M} \mathrm{KCl}$. The wild-type and mutant Spc1 in the cell lysates was probed with anti-phospho-p38 (top) and anti-myc (bottom) antibodies. (C) Spcl phosphorylated on both Thr-171 and Tyr-173 accumulates only transiently after heat shock in wild-type and wis1DD cells. KS2096 (wild type) and KS2086 (wis1DD) strains carrying the spc1:HA6H allele were grown to mid-log phase at $30^{\circ} \mathrm{C}$ in YES medium and shifted to $48^{\circ} \mathrm{C}$ at time 0 . Aliquots of cells were harvested at the indicated time points, and Spcl was purified by Ni-NTA chromatography, which was followed by immunoblotting with antiphospho-p38, anti-phosphotyrosine, and anti-HA antibodies.

sine antibodies, Spc1 phosphorylation after heat shock was examined in wild-type and wis1DD mutant strains. Dual-phosphorylated Spc1 accumulated only transiently after the temperature shift from $30^{\circ} \mathrm{C}$ to $48^{\circ} \mathrm{C}$ in both wild-type and wis1DD strains (Fig. 3C). The peak of dual phosphorylation was observed $\sim 5$ min after heat shock, decreasing rapidly at the following time points, which correlates to the kinetics of Spcl activation after heat shock (Fig. 3A). On the other hand, probing the same samples with anti-phosphotyrosine antibodies showed that the level of Spc1 tyrosine phosphorylation remained high $>20$ min after heat shock (Fig. 3C, middle). Therefore, these data strongly suggest that Spc1 activated by heat shock is rapidly attenuated by dephosphorylation of Thr-171.

\section{PP2C enzymes dephosphorylate Thr-171 of Spc1}

What is the threonine phosphatase that dephosphorylates Spcl after heat shock? Three genes encoding PP2Cs, $p t c 1^{+}, p t c 2^{+}$, and $p t c 3^{+}$, have been identified in $S$. pombe (Shiozaki et al. 1994; Shiozaki and Russell 1995a). Previous genetic data suggested that $p t c 1^{+}$and $p t c 3^{+}$ counteract the wis $1^{+}$gene function: wis1 mutations were isolated as suppressors of the $\Delta p t c 1 \Delta p t c 3$ defects (Shiozaki and Russell 1995a). In addition, $\Delta p t c 1 \Delta p t c 3$ shows a synthetic lethal phenotype with $\Delta p y p 1$, which is rescued by the $\Delta$ wis 1 mutation (Gaits et al. 1997). These observations suggest that the Ptc phosphatases may negatively regulate the Spc1 pathway. To test whether the Ptc phosphatases are involved in dephosphorylation of Spc1 Thr-171, we examined Spc1 phosphorylation after heat shock in various ptc mutants. $\Delta p t c 1, \Delta p t c 2$, and $\Delta p t c 3$ mutations were introduced into the spc1:HA6H strain, and Spcl phosphorylation was probed with antiphospho-p38 and anti-phosphotyrosine antibodies after temperature shift from $30^{\circ} \mathrm{C}$ to $48^{\circ} \mathrm{C}$. None of the single mutations of $\Delta p t c 1, \Delta p t c 2$, and $\Delta p t c 3$ showed significant effect on the Spc1 phosphorylation before and after heat shock (data not shown). However, in the $\Delta p t c 1 \Delta p t c 3$ double mutant, the dual-phosphorylated form of Spc1 decreased more slowly after the initial activation upon heat shock than in wild-type cells (Fig. 4A, top), which was reproducible in repeated experiments. Because tyrosine dephosphorylation of Spc1 was not detected after heat shock in both strains (Fig. 4A, middle), these results indicate that Thr-171 dephosphorylation of Spc1 is compromised in the $\Delta p t c 1 \Delta p t c 3$ mutant. The kinetics of Spc1 dephosphorylation in the $\Delta p t c 1 \Delta p t c 2 \Delta p t c 3$ triple mutant were similar to those in the $\Delta p t c 1 \Delta p t c 3$ double mutant (data not shown), which suggests that Ptc2 may not be important for Spcl dephosphorylation. It is known that type 2A serine/threonine phosphatases (PP2As) dephosphorylate and inactivate mammalian MAPKs (Gómez and Cohen 1991; Alessi et al. 1995). However, mutations in the $S$. pombe PP2A genes ppa1 $1^{+}$ and $\mathrm{ppa}^{+}$(Kinoshita et al. 1990), showed no apparent effect on the phosphorylation state of Spcl both before and after heat shock (data not shown).

If Ptc1 and Ptc3 dephosphorylate Thr-171 of Spc1, overexpression of these phosphatases should lead to a decrease in the level of Thr-171 phosphorylation. ptc $3^{+}$ was overexpressed from the pREP-ptc $3^{+}$plasmid by use of the $n m t 1$ promoter, and phosphorylation of Spc1 after heat shock was examined. Compared with the strain transformed with the pREP vector alone, the level of doubly phosphorylated Spc1 was reduced dramatically in the Ptc3-overexpressing strain (Fig. 4B, top). A very similar result was obtained with a strain overexpressing Ptc1 (data not shown). On the other hand, Ptc3 overproduction exhibited little effect on tyrosine phosphorylation of 

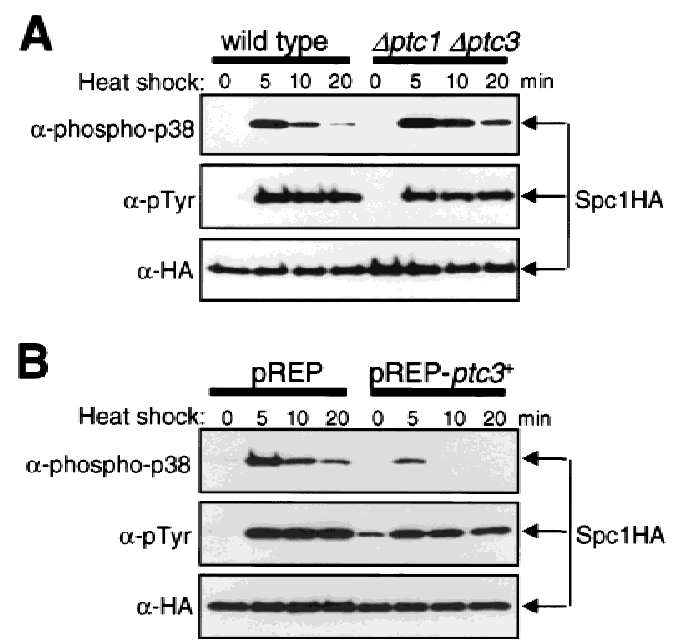

Figure 4. Ptc1 and Ptc 3 phosphatases regulate phosphorylation of Spc1 Thr-171. (A) Wild-type (KS1376) and $\Delta p t c 1 \Delta p t c 3$ mutant (CA135) strains carrying the spc1:HA6H allele were grown at $30^{\circ} \mathrm{C}$ to mid-log phase and shifted to $48^{\circ} \mathrm{C}$ at time 0 . Cells were harvested at the indicated time points and Spcl was purified on Ni-NTA beads for immunoblotting with anti-phospho-p38, anti-phosphotyrosine, and anti-HA antibodies. After the initial Spc1 activation, dual-phosphorylated Spc1 decreased more slowly in $\Delta p t c 1 \Delta p t c 3$ cells than in wild-type cells, a result that was reproduced in repeated experiments. $(B)$ Wild-type spc1:HA6H strain (KS1376) was transformed with the pREP vector and the pREP-ptc $3^{+}$plasmid to express $p t c 3^{+}$under the regulation of the thiamine-repressible $n m t 1$ promoter. The transformants were grown at $30^{\circ} \mathrm{C}$ for $18 \mathrm{hr}$ in EMM2 medium without thiamine to induce expression from the $n m t 1$ promoter before the temperature shift to $48^{\circ} \mathrm{C}$ at time 0 . Cells harvested at the indicated time points were subjected to analyses as described in $A$.

Spc1 upon heat shock, except to cause higher tyrosine phosphorylation in the absence of stress when compared with the control strain (Fig. 4B, middle, time 0). It is possible that the Wis 1 MEK is up-regulated or the Pyp phosphatases are down-regulated to compensate inactivation of Spc1 by Ptc3.

These results strongly suggest that PP2C enzymes Ptc1 and Ptc3 are involved in dephosphorylation of Spc1 Thr-171 to attenuate heat shock-activated Spc1. Consistent with this model, it was observed that Ptcl also dephosphorylated Thr-171 of Spc1 in vitro. GST-Ptc1 fusion protein expressed in Escherichia coli was purified and incubated with phosphorylated GST-Spc1 in the presence and absence of $\mathrm{Mg}^{2+}$, because, like other PP2C enzymes, Ptc1 requires $\mathrm{Mg}^{2+}$ for its activity (Shiozaki et al. 1994). By anti-phospho-p38 immunoblotting, dephosphorylation of GST-Spc1 by GST-Ptc1 was observed in a $\mathrm{Mg}^{2+}$-dependent manner (Fig. 5A, top), whereas no tyrosine dephosphorylation was observed during the experiment (bottom). Furthermore, specific interaction between the Spc1 and Ptcl proteins was also detected by the experiment shown in Figure 5B. GST and GST-Ptc1 immobilized on GSH-beads were incubated with lysates prepared from cells expressing myc-tagged Spc1. Spc1 was coprecipitated with GST-Ptc1 beads but not with
GST beads, indicating specific interaction between Spc1 and Ptc1. No apparent difference was observed between unstressed and heat-shocked cells in the affinity of Spc1 for GST-Ptc1 (Fig. 5B).

These in vivo and in vitro data strongly suggest that Ptc1 and Ptc3 are involved in dephosphorylation of Spc1 Thr-171 to attenuate heat shock-induced activation of Spc1. However, some level of Thr-171 dephosphorylation was still observed in $\Delta p t c 1 \Delta p t c 3$ cells (Fig. 4A), implying that other threonine phosphatases may also dephosphorylate Spc1.

\section{Discussion}

The S. pombe Spc1 SAPK plays crucial roles in the cellular responses to survive severe environmental conditions. Spc1 is strongly activated when cells are exposed to heat shock, and $\Delta s p c 1$ mutant cells lose viability more quickly than wild-type cells at $48^{\circ} \mathrm{C}$ (Degols et al. 1996; Kato et al. 1996), indicating that Spc1 is essential for cellular thermotolerance. Activated Spcl phosphorylates the Atf1 transcription factor to induce various stress response genes (Shiozaki and Russell 1996; Wilkinson et al. 1996) including tps $1^{+}$involved in trehalose synthesis, which is known to be important in the cellular heat

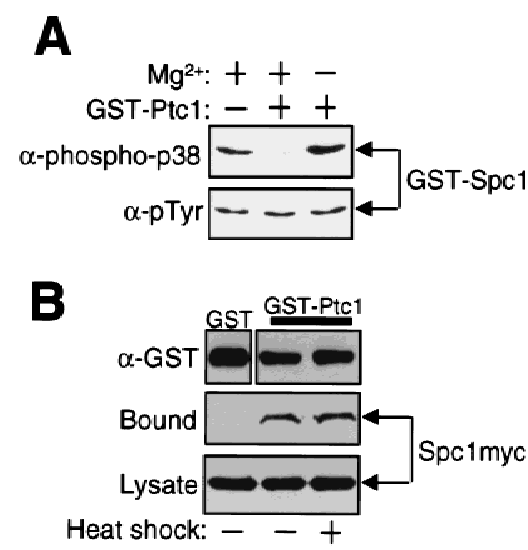

Figure 5. (A) In vitro dephosphorylation of Spc1 Thr-171 by Ptc1. GST-Ptc1 was expressed in E. coli DH5 $\alpha$ and purified by GSH-Sepharose chromatography. Wild-type (PR109) S. pombe strain carrying the pREP1-GST-Spc1 plasmid was grown in EMM2 medium without thiamine to induce expression of GSTSpc1. After a 10-min osmostress by $0.6 \mathrm{M} \mathrm{KCl}$, cells were harvested, and phosphorylated GST-Spc1 was purified on GSHSepharose beads. GST-Ptc1 and GST-Spc1 were incubated in the presence $(+)$ or absence (-) of $20 \mathrm{mM} \mathrm{MgCl}$, and the phosphorylation state of GST-Spc1 was examined by immunoblotting with anti-phospho-p38 and anti-phosphotyrosine antibodies. (B) Physical interaction between Spcl and the Ptcl phosphatase. Strain GD1942 expressing the myc-tagged Spc1 was grown to mid-log phase in YES medium and harvested before and after a 5 -min heat shock at $48^{\circ} \mathrm{C}$. Cell lysates were incubated with bacterially produced GST and GST-Ptc1, which were immobilized on GSH-Sepharose beads. After extensive washes, proteins bound to the beads (top and middle) were detected by immunoblotting with anti-GST and anti-myc antibodies. (bottom) Anti-myc immunoblotting of the total lysates. 
shock response (Blázquez et al. 1994; De Virgilio et al. 1994). In this study, we have explored the regulation of Spc1 in response to heat shock. Our results strongly suggest that heat shock brings about inhibition of the Pyp1 tyrosine phosphatase, which dephosphorylates and inactivates Spc1 (Fig. 6). Because Tyr-173 dephosphorylation by Pypl is a major mechanism for Spcl inactivation, inhibition of Pyp1 is expected to play a key role in activation of Spc1 upon heat shock. Moreover, we have discovered a mechanism that allows only transient activation of Spc1 after heat shock: Thr-171 of Spcl is rapidly dephosphorylated after the initial activation induced by heat shock, whereas Tyr-173 remains phosphorylated. This is the first example showing that MAPK activity is modulated by differential regulation of threonine and tyrosine phosphorylation in response to stimuli.

\section{Stress regulation of the Wis1 MEK}

Previous studies demonstrated that Wis1 is the only MEK for Spc1 (Millar et al. 1995; Shiozaki and Russell

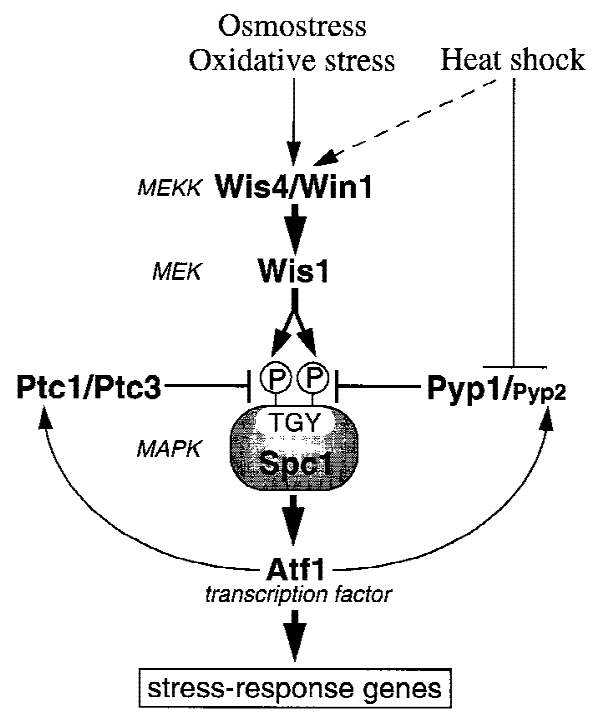

Figure 6. Regulation of the Spc1 SAPK by PP2C and the Pyp tyrosine phosphatases. Spcl is activated by various forms of stress including high osmolarity stress, oxidative stress, and heat shock. The Wis1 MEK activates Spc1 by phosphorylating Thr-171 and Tyr-173. Osmostress and oxidative stress activate Wis1 through phosphorylation of Ser-469/Thr-473, which is carried out by MEKKs, Wis4 and Win1. Heat shock brings about weak activation of Wis1 in a MEKK-dependent manner as well as inhibition of Pyp1 and presumably Pyp2, the Spc1 Tyr-173 phosphatases, which results in strong activation of Spc1. Although Tyr-173 remains phosphorylated in heat-shocked cells because of inhibition of the Pyp phosphatases, Spc1 activity is attenuated by Thr-171 dephosphorylation, which is carried out by Ptc1, Ptc3, and other threonine phosphatases. Transcription of $p y p 2^{+}$and $p t c 1^{+}$is induced by the Spc1-Atf1 pathway in response to stress stimuli, which constitutes dual loops of negative feedback. Expression of $p y p 1^{+}$and $p t c 3^{+}$is constitutive; however, they might be subjected to post-transcriptional regulation. 1995b; Degols et al. 1996), suggesting that Wis1 phosphorylates and activates Spc1 under various stress conditions. However, it had never been examined whether the catalytic activity of Wis1 is increased in response to stress stimuli that induce Spc1 activation. In this study, an in vitro assay for Wis1 activity was developed, and this assay has demonstrated that Wis1 is strongly activated upon osmostress and oxidative stress, whereas only weak, transient activation of Wis1 is detected after heat shock. Modulation of Wisl activity in response to these stress stimuli is dependent on the MEKK phosphorylation sites, Ser-469/Thr-473, of Wis1, suggesting that MEKKs mediate stress signals to Wis1 through phosphorylation of these sites. So far, two MEKKs that phosphorylate and activate Wis1 have been identified, Wis4 (also called Wik1 or Wak1) and Win1 (Samejima et al. 1997, 1998; Shieh et al. 1997; Shiozaki et al. 1997). However, how these MEKKs are regulated in response to stress signals remains unknown. Genetic studies have identified Mcs4 upstream of the Wis4 MEKK (Cottarel 1997; Shieh et al. 1997; Shiozaki et al. 1997); Mcs4 is a protein closely related to the budding yeast Ssk1p, a homolog of the response regulator member of bacterial two-component systems (Maeda et al. 1994). In the $S$. cerevisiae HOG1 cascade, the Ssk2p MEKK is regulated in response to osmostress by a variation of the two-component system, multistep phosphorelay composed of the Sln $1 \mathrm{p}$ histidine kinase, Ypdlp, and Ssk1p (Posas et al. 1998). Therefore, it is likely that regulators homologous to Sln $1 \mathrm{p}$ and Ypdlp also exist upstream of the Spcl cascade. However, relatively weak activation of Wis1 upon heat shock implies that those upstream regulators might not be fully operational under extreme environment such as high temperature. It is also possible that a sensor dedicated for heat shock stimuli might never have evolved upstream of the SAPK cascades.

\section{Regulation of MAPKs by threonine- and tyrosine- specific phosphatases}

Evidence presented in this report strongly suggests that Pyp1, the major tyrosine phosphatase for Spc1, is inhibited upon heat shock. First, tyrosine phosphorylation of Spcl becomes very stable in heat-shocked cells, which contrasts with rapid dephosphorylation of Spc1 after osmostress. Second, heat shock induces strong activation of Spcl even in the strain overexpressing Pyp1. Third, experiments with $\mathrm{Pyp} 1^{\mathrm{C} 470 \mathrm{~S}}$ indicate that the interaction of Pyp1 with Spc1 is rapidly lost after heat shock. Recently, we found that Pyp1 is a soluble protein in unstressed cells but the majority of Pyp 1 becomes insoluble within $10 \mathrm{~min}$ when cells are exposed to heat shock (A.N. Nguyen and K. Shiozaki, unpubl.). This change in the solubility of Pyp1 is not accompanied by an alteration of its cellular localization: By immunofluorescence microscopy, Pyp1 is a cytoplasmic protein, and Pyp1 localization is not affected by heat shock (A.N. Nguyen and K. Shiozaki, unpubl.). One possible explanation for these results is that, upon heat shock, Pyp1 protein is subjected to changes in conformation, modification, or 
interaction with other proteins. The Pyp2 protein also becomes insoluble in heat-shocked cells (A.N. Nguyen and K. Shiozaki, unpubl.), which may suggest that Pyp2 is also inactivated after heat shock. Previously, Samejima et al. (1997) also suggested Pyp1 inhibition as a mechanism for Spc1 activation upon heat shock, which was based on their failure to detect heat shock-induced activation of Spc1 in $\Delta p y p 1$ mutants. However, we and others have demonstrated that heat shock and other forms of stress can bring about Spc1 activation in $\Delta p y p 1$ cells (Shieh et al. 1998; Shiozaki et al. 1998). It is likely that, in $\Delta p y p 1$ mutants, weak activation of Wis1 and inhibition of Pyp2 cause further Spc1 activation upon heat shock.

In unstressed cells, Spc1 is kept inactive mainly through dephosphorylation of Tyr-173, which is carried out by two tyrosine-specific phosphatases, Pyp1 and Pyp2; first, mutational inactivation of Pyp1 brings about phenotypes similar to those of the strain expressing the constitutively active Wis1DD (Shiozaki et al. 1998). Second, simultaneous deletion of the $p y p 1^{+}$and $p y p 2^{+}$genes induces hyperactivation of Spc1, which is lethal to the cell (Millar et al. 1995; Shiozaki and Russell 1995b). Third, we observed that mutational inactivation of pyp $1^{+}$is sufficient to induce a significant increase of dual-phosphorylated, active Spcl (data not shown). These observations may suggest that unstressed cells have only limited activity to dephosphorylate Spc1 Thr171. Thus, when cells are exposed to heat shock, inhibition of the Pyp phosphatases, combined with transient, moderate activation of Wis1, induces strong activation of Spc1. In contrast, osmostress and oxidative stress induce Spc1 activation solely in a MEKK-dependent manner (Shiozaki et al. 1998). SAPK activation by inhibition of the SAPK phosphatase has also been proposed for $\mathrm{As}^{3+}$-induced activation of JNK [c-Jun amino (N)-terminal kinase; Cavigelli et al. 1996], although the identity of the JNK phosphatase remains unknown. We found that, like heat shock, $\mathrm{As}^{3+}$ also impairs the interaction of Pyp1 with Spc1, resulting in Spcl activation (A.N. Nguyen and K. Shiozaki, unpubl.). An attractive model would be that SAPK phosphatases sensitive to certain types of stress can serve as stress sensors.

Following the initial activation induced by heat shock, Spc1 is rapidly inactivated by Thr-171 dephosphorylation. Our data strongly suggest that PP2C enzymes encoded by $p t c 1^{+}$and $p t c 3^{+}$are involved in this attenuation mechanism. However, dephosphorylation of Spc1 Thr171 is not completely abolished in the $\Delta p t c 1 \Delta p t c 3 \mathrm{mu}-$ tant, suggesting that other threonine phosphatases may also be involved in Spc1 inactivation after heat shock. Ptc1, Ptc2, and Ptc3 do not account for all the cellular PP2C activity in S. pombe (Shiozaki and Russell 1995a), and Spcl dephosphorylation may involve additional PP2C enzymes that are not yet identified. Transcription of $p t c 1^{+}$is regulated by the Spc1-Atf1 pathway (Gaits et al. 1997), and $p t c 1^{+}$expression is induced in response to heat shock (Shiozaki et al. 1994), which may be important for swift attenuation of Spc1 activity (Fig. 6). It has been reported recently that $\mathrm{PP} 2 \mathrm{C}$ inhibits the mamma- lian p38 and JNK pathways in transient transfection assays and that PP2C dephosphorylates the threonine residue of p38 in vitro (Takekawa et al. 1998). Although the physiological role of SAPK inhibition by PP2C in mammalian cells is unknown, these observations suggest that the PP2C function in SAPK inhibition is evolutionarily conserved. However, our findings do not exclude the possibility that PP2C also regulates events downstream of the SAPKs (Gaits et al. 1997).

Dual-specificity phosphatases that can dephosphorylate both threonine and tyrosine residues are known to inactivate many members of the MAPK family (Hunter 1995; Keyse 1995), including SAPKs (Liu et al. 1995; Raingeaud et al. 1995; Gupta et al. 1996; Hirsch and Stork 1997). Data presented here, however, clearly demonstrate that transient activation of Spc1 upon heat shock is brought about through differential regulation of Thr-171 and Tyr-173 phosphorylation. MAPK regulation by tyrosine-specific phosphatases has also been reported in budding yeast (Jacoby et al. 1997; Wurgler-Murphy et al. 1997; Zhan et al. 1997) and mammalian cells (Alessi et al. 1995; Ogata et al. 1999). Dual phosphorylation is a common activation mechanism for all MAPKs, and differential dephosphorylation of the threonine and tyrosine residues allows two distinct inputs to a MAPK. Therefore, the regulatory mechanism we described here could prove to be widespread in other MAPK pathways of lower and higher eukaryotes.

\section{Materials and methods}

Yeast strains and general techniques

S. pombe strains used in this study are listed in Table 1. They are derivatives of $972 h^{-}$and $975 h^{+}$(Mitchison 1970). Growth media and basic genetic and biochemical techniques for $S$. pombe have been described (Moreno et al. 1991; Alfa et al. 1993). S. pombe cells were grown in yeast extract medium YES and synthetic minimal medium EMM2.

\section{In vitro assay for Wis1 activity}

In strain KS1878 and KS2125, the chromosomal wis $1^{+}$gene is replaced by the wild-type wis1 and wis1DD mutant genes, respectively, which are tagged with sequence encoding 12 copies of the myc epitope (Shiozaki et al. 1998). These strains were grown to early logarithmic phase in YES medium at $30^{\circ} \mathrm{C}$ and then treated with $0.6 \mathrm{M} \mathrm{KCl}$ for $10 \mathrm{~min}$ (osmostress), $0.3 \mathrm{~mm}$ $\mathrm{H}_{2} \mathrm{O}_{2}$ for $10 \mathrm{~min}$ (oxidative stress), or shifted to $48^{\circ} \mathrm{C}$ for heat shock (Shiozaki et al. 1997). Cells were lysed in IP lysis buffer [50 mM Tris- $\mathrm{HCl}$ (pH 7.2), 5 mм EDTA, $150 \mathrm{~mm} \mathrm{NaCl}, 1 \mathrm{~mm}$ 2-mercaptoethanol, 10\% glycerol, $\left.50 \mathrm{~mm} \mathrm{NaF}, 0.1 \mathrm{mM} \mathrm{Na}_{3} \mathrm{VO}_{4}\right]$ containing a protease inhibitor cocktail. The homogenate was centrifuged at $12,000 \mathrm{~g}$ for $10 \mathrm{~min}$, and the supernatant was incubated for $40 \mathrm{~min}$ at $4^{\circ} \mathrm{C}$ with polyclonal anti-myc antibodies (Santa Cruz Biotechnology) conjugated to protein A-Sepharose. After extensive washes with IP lysis buffer supplemented with $0.5 \%$ Triton X-100, immunoprecipitated Wis1myc and Wis1DDmyc were incubated with GST-Spc1 in kinase reaction buffer [25 mM Tris- $\mathrm{HCl}$ (pH 7.2), $10 \mathrm{~mm} \mathrm{MgCl} 2,50 \mathrm{~mm} \mathrm{NaCl}, 50$ $\mu \mathrm{M}$ ATP, $10 \mathrm{~mm}$ glutathione, $\left.50 \mu \mathrm{g} / \mathrm{ml} \mathrm{BSA}, 0.1 \mathrm{~mm} \mathrm{Na}_{3} \mathrm{VO}_{4}\right]$ at $30^{\circ} \mathrm{C}$ for $10 \mathrm{~min}$. Purification of unphosphorylated GST-Spc1 from a $\Delta$ wis1 strain (JM544) has been described previously 
Table 1. S. pombe strains used in this study

\begin{tabular}{|c|c|c|}
\hline Strain & Genotype & Source or reference \\
\hline PR109 & & lab stock \\
\hline JM544 & wis1::ura4 ${ }^{+}$ & lab stock \\
\hline KS1366 & spc1::ura4 ${ }^{+}$ & lab stock \\
\hline CA140 & his7 spc1AY:12myc(ura4 $\left.{ }^{+}\right)$ & Gaits et al. (1998) \\
\hline KS1376 & $\operatorname{spc1:HA6H}\left(\mathrm{ura}^{+}\right)$ & Shiozaki and Russell (1995) \\
\hline KS1878 & spc1::ura4 $4^{+}$wis1:12myc(ura4 $\left.{ }^{+}\right)$ & Shiozaki et al. (1998) \\
\hline GD1942 & spc1:12myc(ura4 $\left.{ }^{+}\right)$ & Gaits et al. (1998) \\
\hline GD1953 & pур 1:12myc $\left(\right.$ urat $\left.^{+}\right)$ & Gaits and Russell (1999) \\
\hline KS2088 & spc1:HA6H(ura4 $\left.{ }^{+}\right)$wis1DD:12myc $\left(\right.$ura4 $\left.^{+}\right)$ & Shiozaki et al. (1998) \\
\hline KS2096 & spc1:HA6H(ura4 $\left.{ }^{+}\right)$wis1:12myc(ura4 $\left.{ }^{+}\right)$ & Shiozaki et al. (1998) \\
\hline KS2125 & spc1::ura4+ wis1DD:12myc(ura4 $\left.4^{+}\right)$ & Shiozaki et al. (1998) \\
\hline CA98 & ppa2:: ura4 $4^{+}$spc1:HA6H(ura4 $\left.4^{+}\right)$ & this study \\
\hline CA129 & ppa1::ura4 ${ }^{+}$spc1:HA6H(ura4 $\left.{ }^{+}\right)$ & this study \\
\hline CA135 & his7-366 ptc1::LEU2 ptc3::his $7^{+}$spc1:HA6H(ura4 $\left.{ }^{+}\right)$ & this study \\
\hline CA142 & ptc2::ura4 $4^{+}$spc1:HA6H(ura4 $\left.{ }^{+}\right)$ & this study \\
\hline CA143 & ptc1::LEU2 spc1HA6H(ura4 $\left.4^{+}\right)$ & this study \\
\hline CA145 & ptc3::his $7^{+}$spc1:HA6H(ura4 $\left.4^{+}\right)$ & this study \\
\hline CA148 & his7-366 ptc1::LEU2 ptc2::ura4 $4^{+}$ptc3::his $7^{+}$spc1:HA6H(ura4 $\left.{ }^{+}\right)$ & this study \\
\hline CA171 & pyp $1::$ ura4 $^{+}$spc1:HA6H(ura4 $\left.{ }^{+}\right)$ & this study \\
\hline CA187 & pyp1-C470S:12myc(ura4 $\left.{ }^{+}\right)$ & this study \\
\hline
\end{tabular}

All strains are $h^{-}$leu1-32 ura4-D18.

(Shiozaki and Russell 1995b). The samples were analyzed by SDS-PAGE followed by immunoblotting with monoclonal anti-phosphotyrosine (Upstate Biotechnology) and anti-myc (BAbCO) antibodies. Under the experimental conditions used, we observed a linear increase of GST-Spc1 phosphorylation by Wis1DD along the time course of reaction up to $20 \mathrm{~min}$.

\section{Purification and detection of the Spc1HA6H protein}

KS1376, KS2088 (wis1DD:myc), KS2096 (wis1:myc), CA98

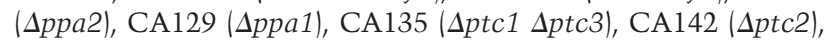

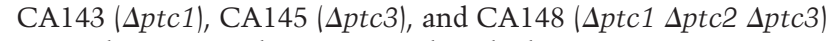
carry chromosomal $s p c 1^{+}$tagged with the $\mathrm{HA} 6 \mathrm{H}$ sequence encoding two copies of the HA epitope and six consecutive histidine residues (Shiozaki and Russell 1995b, 1997). Spc1HA6H protein was purified on Ni-NTA-agarose beads under denaturing conditions and analyzed by immunoblotting with anti-HA (12CA5), anti-phosphotyrosine, and anti-phospho-p38 MAPK (New England Biolabs) antibodies (Shiozaki and Russell 1997). Stress treatments of $S$. pombe cells by $\mathrm{KCl}, \mathrm{H}_{2} \mathrm{O}_{2}$, and heat shock were performed as described previously (Shiozaki et al. 1997). Cells were harvested by rapid filtration (Shiozaki and Russell 1997), which appears to be less stressful to the cells than centrifugation (Shiozaki et al. 1998).

\section{Construction of the pyp1-C470S:myc allele}

The pyp1-C470S sequence (Shiozaki and Russell 1995b) was amplified by PCR and cloned into the pRIP-12myc vector as described previously (Gaits et al. 1998). The plasmid was linearized at the MscI site of pyp1-C470S and used to transform a wild-type strain (PR109). Integration of pyp1-C470S:12myc to the $p y p 1^{+}$locus was confirmed by Southern hybridization. The resultant pyp1-C470S:12myc strain (CA187) was transformed with pREP1-GST-Spc1 (Shiozaki and Russell 1995b), and the transformant was grown at $30^{\circ} \mathrm{C}$ in EMM2 medium without thiamine to induce expression of GST-Spc1 from the thiaminerepressible nmt1 promoter (Maundrell 1990). Cells were exposed to heat shock at $48^{\circ} \mathrm{C}$ or $0.6 \mathrm{M} \mathrm{KCl}$ for osmostress, har- vested by filtration and frozen in liquid nitrogen. GST-Spc1 was collected on GSH-Sepharose beads from cell lysates as described (Shiozaki and Russell 1995b). After extensive washes, proteins bound to the beads were analyzed by immunoblotting with anti-GST and anti-myc antibodies.

\section{In vitro assay for Spc1 activity}

spc1:myc cells (GD1942) were grown to early logarithmic phase in YES medium at $30^{\circ} \mathrm{C}$ and then shifted to $48^{\circ} \mathrm{C}$ for heat shock. Harvested cells were lysed in IP lysis buffer and Spclmyc was purified by immunoprecipitation with polyclonal anti-myc antibodies (Santa Cruz Biotechnology) conjugated to Protein A-Sepharose. As substrate, GST-Atf1 was expressed in the $\Delta$ spc1 strain (KS1366) and unphosphorylated GST-Atf1 was purified on GSH-Sepharose beads (Shiozaki and Russell 1997). Then, Spc1myc and GST-Atf1 were incubated in KA buffer [25 $\mathrm{mm}$ Tris- $\mathrm{HCl}$ (pH 7.2), $10 \mathrm{~mm} \mathrm{MgCl}, 0.1 \mathrm{~mm} \mathrm{Na}_{3} \mathrm{VO}_{4}, 10 \mathrm{~mm}$ glutathione] containing $50 \mu \mathrm{M}\left[\gamma^{-32} \mathrm{P}\right] \mathrm{ATP}$ at $25^{\circ} \mathrm{C}$ for $10 \mathrm{~min}$. Samples were subjected to SDS-PAGE, which was followed by autoradiography and immunoblotting with anti-myc antibodies.

\section{In vitro dephosphorylation of Spc1 by GST-Ptc1}

GST and GST-Ptc1 were expressed in E. coli DH5 $\alpha$ cells and purified on GSH-Sepharose beads as described previously (Shiozaki et al. 1994). Wild-type S. pombe cells (PR109) transformed with pREP1-GST-Spc1 were grown in EMM2 medium without thiamine to induce expression of GST-Spc1. Then, cells were stressed with $0.6 \mathrm{M} \mathrm{KCl}$ in EMM2 for $10 \mathrm{~min}$, and phosphorylated GST-Spc1 was purified on GSH-Sepharose beads (Shiozaki and Russell 1995b). GST-Ptc1 and GST-Spc1 bound to the beads were mixed and incubated in Solution A [50 $\mathrm{mm}$ Tris-HCl (pH 7.0), $0.1 \mathrm{~mm}$ EGTA, $1 \mathrm{mg} / \mathrm{ml} \mathrm{BSA}, 10 \mathrm{~mm}$ glutathione] in the presence of $20 \mathrm{mM} \mathrm{MgCl}_{2}$ or $1 \mathrm{~mm}$ EDTA at $30^{\circ} \mathrm{C}$ for $30 \mathrm{~min}$. Samples were analyzed by immunoblotting with anti-phospho-p38 MAPK and anti-phosphotyrosine antibodies. For in vitro binding assays between Ptc1 and Spc1, the 
spc1:12myc strain (GD1942) was grown in YES medium at $30^{\circ} \mathrm{C}$, and aliquots were harvested before and after a 5-min heat shock at $48^{\circ} \mathrm{C}$. Cells were lysed in IP lysis buffer containing $0.5 \%$ Triton X-100 and centrifuged at $12,000 \mathrm{~g}$ for $10 \mathrm{~min}$ at $4{ }^{\circ} \mathrm{C}$. The supernatant was incubated with GST or GST-Ptc1 bound to GSH-Sepharose beads at $4^{\circ} \mathrm{C}$ for $25 \mathrm{~min}$ on a rocking platform. The beads were then washed four times with IP lysis buffer containing $1 \%$ Triton X-100, and proteins bound to the beads were analyzed by immunoblotting with anti-GST and anti-myc antibodies.

\section{Acknowledgments}

We thank Albert Lee for technical assistance, Frédérique Gaits, Geneviève Degols, Paul Russell, and Mitsuhiro Yanagida for strains, Jodi Nunnari, Chester Price, Paul Russell, and Mitsuhiro Yanagida for helpful discussion and critical reading of the manuscript. This research was supported in part by grant IRG95-125-04 from the American Cancer Society.

The publication costs of this article were defrayed in part by payment of page charges. This article must therefore be hereby marked 'advertisement' in accordance with 18 USC section 1734 solely to indicate this fact.

\section{References}

Alessi, D.R., N. Gómez, G. Moorhead, T. Lewis, S.M. Keyse, and P. Cohen. 1995. Inactivation of p42 MAP kinase by protein phosphatase $2 \mathrm{~A}$ and a protein tyrosine phosphatase, but not CL100, in various cell lines. Curr. Biol. 5: 283-295.

Alfa, C., P. Fantes, J. Hyams, M. McLeod, and E. Warbrick. 1993. Experiments with fission yeast: A laboratory course manual. Cold Spring Harbor Laboratory Press, Cold Spring Harbor, NY.

Blázquez, M.A., R. Stucka, H. Feldmann, and C. Gancedo. 1994. Trehalose-6-P synthase is dispensable for growth on glucose but not for spore germination in Schizosaccharomyces pombe. J. Bacteriol. 176: 3895-3902.

Brewster, J.L., T. de Valoir, N.D. Dwyer, E. Winter, and M.C. Gustin. 1993. An osmosensing signal transduction pathway in yeast. Science 259: 1760-1763.

Cavigelli, M., W.W. Li, A. Lin, B. Su, K. Yoshioka, and M. Karin. 1996. The tumor promoter arsenite stimulates AP-1 activity by inhibiting a JNK phosphatase. EMBO J. 15: 6269-6279.

Clarke, P.R. 1994. Switching off MAP kinases. Curr. Biol. 4: 647-650.

Cobb, M.H. and E.J. Goldsmith. 1995. How MAP kinases are regulated. J. Biol. Chem. 270: 14843-14846.

Cottarel, G. 1997. Mcs4, a two-component system response regulator homologue, regulates the Schizosaccharomyces pombe cell cycle control. Genetics 147: 1043-1051.

De Virgilio, C., T. Hottiger, J. Dominguez, T. Boller, and A. Wiemken. 1994. The role of trehalose synthesis for the acquisition of thermotolerance in yeast. Genetic evidence that trehalose is a thermoprotectant. Eur. I. Biochem. 219: 179186.

Degols, G., K. Shiozaki, and P. Russell. 1996. Activation and regulation of the Spcl stress-activated protein kinase in Schizosaccharomyces pombe. Mol. Cell. Biol. 16: 28702877.

Gaits, F. and P. Russell. 1999. Active nucleocytoplasmic shuttling required for function and regulation of stress-activated kinase Spc1/Sty1 in fission yeasts. Mol. Biol. Cell 10: 13951407.

Gaits, F., K. Shiozaki, and P. Russell. 1997. Protein phosphatase $2 \mathrm{C}$ acts independently of stress-activated kinase cascade to regulate the stress response in fission yeast. J. Biol. Chem. 272: $17873-17879$.

Gaits, F., G. Degols, K. Shiozaki, and P. Russell. 1998. Phosphorylation and association with the transcription factor Atf1 regulate localization of Spc1/Styl stress-activated kinase in fission yeast. Genes \& Dev. 12: 1464-1473.

Gómez, N. and P. Cohen. 1991. Dissection of the protein kinase cascade by which nerve growth factor activates MAP kinases. Nature 353: 170-173.

Gupta, S., T. Barrett, A.J. Whitmarsh, J. Cavanagh, H.K. Sluss, B. Derijard, and R.J. Davis. 1996. Selective interaction of JNK protein kinase isoforms with transcription factors. $E M B O J$. 15: $2760-2770$.

Han, J., J.-D. Lee, L. Bibbs, and R.J. Ulevitch. 1994. A MAP kinase targeted by endotoxin and hyperosmolarity in mammalian cells. Science 265: 808-811.

Hirsch, D.D. and P.J. Stork. 1997. Mitogen-activated protein kinase phosphatases inactivate stress-activated protein kinase pathways in vivo. J. Biol. Chem. 272: 4568-4575.

Hunter, T. 1995. Protein kinases and phosphatases: The yin and yang of protein phosphorylation and signaling. Cell 80: 225236.

Jacoby, T., H. Flanagan, A. Faykin, A.G. Seto, C. Mattison, and I. Ota. 1997. Two protein-tyrosine phosphatases inactivate the osmotic stress response pathway in yeast by targeting the mitogen-activated protein kinase, Hog1. J. Biol. Chem. 272: 17749-17755.

Kato, T.J., K. Okazaki, H. Murakami, S. Stettler, P.A. Fantes, and H. Okayama. 1996. Stress signal, mediated by a Hog1like MAP kinase, controls sexual development in fission yeast. FEBS Lett. 378: 207-212.

Keyse, S.M. 1995. An emerging family of dual specificity MAP kinase phosphatases. Biochim. Biophys. Acta 1265: 152160.

1998. Protein phosphatases and the regulation of MAP kinase activity. Semin. Cell Dev. Biol. 9: 143-152.

Kinoshita, N., H. Ohkura, and M. Yanagida. 1990. Distinct, essential roles of type 1 and $2 \mathrm{~A}$ protein phosphatases in the control of the fission yeast cell division cycle. Cell 63: 405415.

Kyriakis, J.M. and J. Avruch. 1996. Sounding the alarm: Protein kinase cascades activated by stress and inflammation. J. Biol. Chem. 271: 24313-24316.

Liu, Y., M. Gorospe, C. Yang, and N.J. Holbrook. 1995. Role of mitogen-activated protein kinase phosphatase during the cellular response to genotoxic stress. Inhibition of c-Jun amino-terminal kinase activity and AP-1-dependent gene activation. J. Biol. Chem. 270: 8377-8380.

Maeda, T., S.M. Wurgler-Murphy, and H. Saito. 1994. A twocomponent system that regulates an osmosensing MAP kinase cascade in yeast. Nature 369: 242-245.

Marshall, C.J. 1995. Specificity of receptor tyrosine kinase signaling: Transient versus sustained extracellular signal-regulated kinase activation. Cell 80: 179-185.

Maundrell, K. 1990. nmt1 of fission yeast. I. Biol. Chem. 265: 10857-10864.

Millar, J.B.A., V. Buck, and M.G. Wilkinson. 1995. Pyp1 and Pyp2 PTPases dephosphorylate an osmosensing MAP kinase controlling cell size at division in fission yeast. Genes \& Dev. 9: 2117-2130.

Mitchison, J.M. 1970. Physiological and cytological methods for Schizosaccharomyces pombe. Methods Cell Physiol. 4: 131146.

Moreno, S., A. Klar, and P. Nurse. 1991. Molecular genetic analysis of fission yeast Schizosaccharomyces pombe. Methods Enzymol. 194: 795-823. 
Ogata, M., M. Oh-hora, A. Kosugi, and T. Hamaoka. 1999. Inactivation of mitogen-activated protein kinases by a mammalian tyrosine-specific phosphatase, PTPBR7. Biochem. Biophys. Res. Commun. 256: 52-56.

Posas, F., M. Takekawa, and H. Saito. 1998. Signal transduction by MAP kinase cascades in budding yeast. Curr. Opin. Microbiol. 1: 175-182.

Raingeaud, J., S. Gupta, J. Rogers, M. Dickens, J. Han, R. Ulevitch, and R. Davis. 1995. Pro-inflammatory cytokines and environmental stress cause p38 mitogen-activated protein kinase activation by dual phosphorylation on tyrosine and threonine. J. Biol. Chem. 270: 7420-7426.

Samejima, I., S. Mackie, and P.A. Fantes. 1997. Multiple modes of activation of the stress-responsive MAP kinase pathway in fission yeast. $E M B O J .16: 6162-6170$.

Samejima, I., S. Mackie, E. Warbrick, R. Weisman, and P.A. Fantes. 1998. The fission yeast mitotic regulator win $1^{+}$encodes a MAP kinase kinase kinase that phosphorylates and activates Wis1 MAP kinase kinase in response to high osmolarity. Mol. Biol. Cell 9: 2325-2335.

Shieh, J.-C., M.G. Wilkinson, V. Buck, B.A. Morgan, K. Makino, and J.B.A. Millar. 1997. The Mcs4 response regulator coordinately controls the stress-activated Wak1-Wis1-Sty1 MAP kinase pathway and fission yeast cell cycle. Genes \& Dev. 11: 1008-1022.

Shieh, J.C., H. Martin, and J.B.A. Millar. 1998. Evidence for a novel MAPKKK-independent pathway controlling the stress activated Sty1/Spc1 MAP kinase in fission yeast. J. Cell Sci. 111: 2799-2807.

Shiozaki, K. and P. Russell. 1995a. Counteractive roles of protein phosphatase 2C and a MAP kinase kinase homolog in the osmoregulation of fission yeast. EMBO J. 14: 492-502.

- 1995b. Cell-cycle control linked to the extracellular environment by MAP kinase pathway in fission yeast. Nature 378: 739-743.

. 1996. Conjugation, meiosis, and the osmotic stress response are regulated by Spc1 kinase through Atf1 transcription factor in fission yeast. Genes \& Dev. 10: 2276-2288.

. 1997. Stress-activated protein kinase pathway in cell cycle control of fission yeast. Methods Enzymol. 283: 506520 .

Shiozaki, K., H. Akhavan-Niaki, C.H. McGowan, and P. Russell. 1994. Protein phosphatase $2 \mathrm{C}$ encoded by $p t c 1^{+}$is important in the heat shock response of fission yeast. Mol. Cell. Biol. 14: 3743-3751.

Shiozaki, K., M. Shiozaki, and P. Russell. 1997. Mcs4 mitotic catastrophe suppressor regulates the fission yeast cell cycle through the Wik1-Wis1-Spcl kinase cascade. Mol. Biol. Cell 8: 409-419.

. 1998. Heat stress activates fission yeast Spc1/Styl MAPK by a MEKK-independent mechanism. Mol. Biol. Cell 9: 1339-1349.

Takekawa, M., T. Maeda, and H. Saito. 1998. Protein phosphatase $2 \mathrm{C} \alpha$ inhibits the human stress-responsive p38 and JNK MAPK pathways. EMBO J. 17: 4744-4752.

Warbrick, E. and P.A. Fantes. 1991. The wis1 protein is a dosagedependent regulator of mitosis in Schizosaccharomyces pombe. EMBO J. 10: 4291-4299.

Waskiewicz, A.J. and J.A. Cooper. 1995. Mitogen and stress response pathways: MAP kinase cascades and phosphatase regulation in mammals and yeast. Curr. Opin. Cell Biol. 7: 798-805

Wilkinson, M.G., M. Samuels, T. Takeda, W.M. Toone, J.-C. Shieh, T. Toda, J.B.A. Millar, and N. Jones. 1996. The Atf1 transcription factor is a target for the Styl stress-activated
MAP kinase pathway in fission yeast. Genes \& Dev. 10: 2289-2301.

Wurgler-Murphy, S.M., T. Maeda, E.A. Witten, and H. Saito. 1997. Regulation of the Saccharomyces cerevisiae HOG1 mitogen-activated protein kinase by the PTP2 and PTP3 protein tyrosine phosphatases. Mol. Cell. Biol. 17: 1289-1297.

Zhan, X.L., R.J. Deschenes, and K.L. Guan. 1997. Differential regulation of FUS3 MAP kinase by tyrosine-specific phosphatases PTP2/PTP3 and dual-specificity phosphatase MSG5 in Saccharomyces cerevisiae. Genes \& Dev. 11: 1690-1702. 


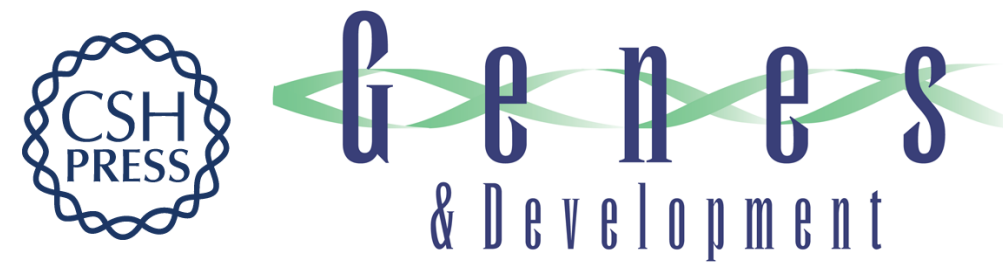

\section{Heat shock-induced activation of stress MAP kinase is regulated by threonine- and tyrosine-specific phosphatases}

Aaron Ngocky Nguyen and Kazuhiro Shiozaki

Genes Dev. 1999, 13:

References This article cites 49 articles, 27 of which can be accessed free at:

http://genesdev.cshlp.org/content/13/13/1653.full.html\#ref-list-1

License

Email Alerting Receive free email alerts when new articles cite this article - sign up in the box at the top Service right corner of the article or click here.

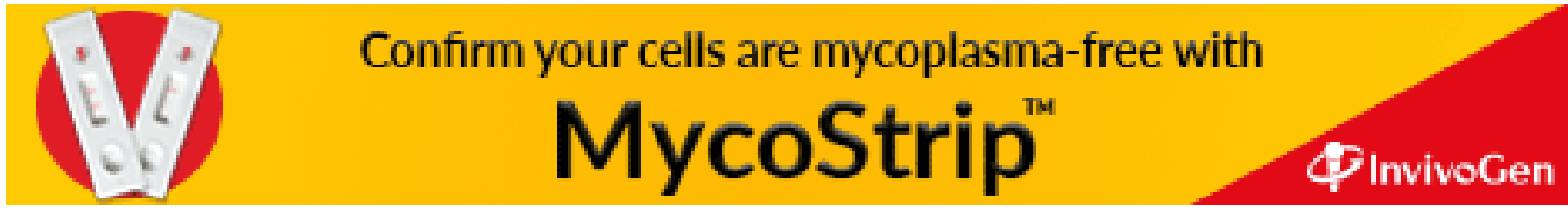

